'Grupo de Estudios de Ética Clínica, Sociedad Médica de Santiago. Santiago, Chile. 2Hospital Naval "Almirante Nef". Viña del Mar, Chile. ${ }^{3}$ Centro de Bioética, Pontificia Universidad Católica de Chile. Santiago, Chile.

${ }^{4}$ Facultad de Medicina, Universidad de Chile. Santiago, Chile. ${ }^{5}$ Academia Chilena de Medicina, Instituto de Chile.

${ }^{6}$ Clínica Avansalud. Santiago, Chile. ${ }^{7}$ Facultad de Medicina, Pontificia Universidad Católica de Chile Santiago, Chile.

${ }^{8}$ Facultad de Medicina, Universidad de los Andes. Santiago, Chile.

${ }^{9}$ Facultad de Medicina, Universidad Andrés Bello. Viña del Mar, Chile. ${ }^{10}$ Clínica Santa María. Santiago, Chile.

Manuscrito por invitación del Editor Recibido el 10 de octubre de 2015 aceptado el 30 de octubre de 2015.

Este documento presenta la opinión de los miembros del Grupo de Estudios de Ética Clínica de la Sociedad Médica de Santiago, sin haber sido sometido al juicio de su Directorio, por lo cual no es un documento oficial de esta Sociedad. Los autores declaran no tener conflictos de intereses La Dra. Carolina Herrera C. tiene, adicionalmente, un contrato de trabajo con el Laboratorio Novartis, Chile, donde se desempeña como "Clinical Advisor Respiratory".

Correspondencia a: Dr. Carlos Echeverría B. Hospital Naval "Almirante Nef". Subida Alessandri $s / n$ Viña del Mar. Chile. ciecheverria@hotmail.com

\section{Consideraciones acerca de la "interrupción voluntaria del embarazo", desde el punto de vista ético-médico (a propósito de un proyecto de ley)}

\author{
CARLOS ECHEVERRÍA B. ${ }^{1,2}$, ALEJANDRO SERANI M. ${ }^{1,3}$, \\ ANA MARÍA ARRIAGADA U. ${ }^{1,4}$, ALEJANDRO GOIC G. ${ }^{1,5}$, \\ CAROLINA HERRERA C. ${ }^{1,6}$, CARLOS QUINTANA V. ${ }^{1,7,8}$, \\ ALBERTO ROJAS O. ${ }^{1,9}$, GONZALO RUIZ-ESQUIDE ${ }^{1,10}$, \\ RODRIGO SALINAS R. ${ }^{1,4}$, PAULINA TABOADA R. ${ }^{1,3}$, \\ RICARDO VACAREZZA Y. ${ }^{1,4}$
}

\section{An ethical and medical perspective on the voluntary termination of pregnancy}

"Voluntary termination of pregnancy" can refer to actions intended to make a delivery easier, to provide medical care to the fetus, or to protect the life or health of the mother. All of these are proper medical actions and are by definition voluntary. In other cases, the expression denotes a termination of pregnancy before the embryo or fetus is viable, leading to the death of the latter. This action is constitutive of abortion under current Chilean law. The product of conception living being, who develops in the womb during pregnancy, is an individual, both in the sense that it is different from its mother and father, and in that it is a biological individual. For these reasons, such living being constitutes another patient in itself. The free and voluntary medical action of health care professionals is geared toward disease prevention or health recovery and medical terminations of pregnancy, as distinguished from abortion, are not criminalized in our country. Therefore, the idea of legalizing abortive terminations of pregnancy so that they become "legitimate health care services" is a call to the medical community, which should engage in a debate about the meaning and consequences of an eventual mandate of the State that would be at odds with the Hippocratic tradition. A woman can feel that her health is at risk due to her pregnancy, and she certainly has the right to request medical help. Health professionals should care both at the medical and emotional level for all those who require their services, especially when such persons are undergoing situations of vulnerability and distress. When requested to perform an abortion, the physician faces dilemmas that should be addressed in line with the present state of the medical art.

(Rev Med Chile 2015; 143: 1478-1483)

Key words: Abortion, legal; Abortion, criminal; Pregnancy, unwanted; Rape; Fetal viability. 
E Grupo de Estudios de Ética Clínica de la Sociedad Médica de Santiago-Sociedad Chilena de Medicina Interna, respondiendo a sus objetivos y las circunstancias actuales, ha considerado un deber dar a conocer su opinión frente a un proyecto de ley, actualmente en discusión en el Congreso Nacional ${ }^{1}$, que "regula la despenalización de la interrupción voluntaria del embarazo en tres causales". Se trata de un proyecto que incide directamente en el ejercicio de nuestra profesión. Pensamos que esta reflexión podría ayudar a esclarecer algunos puntos de la discusión, al ilustrar las opciones que cada médico pueda y deba tener como profesional y ciudadano.

\section{Antecedentes}

Las variadas circunstancias que conducen a plantearse la realización de un aborto, más allá de lo estrictamente médico, son ciertamente dolorosas y dramáticas. El aborto está presente en muchas sociedades, con grados variables de aceptación o rechazo, y sus condicionantes son complejísimos. Confluyen hacia su realización una sumatoria inmensa de carencias y violencias que afectan a las personas, a las familias y a la sociedad. Hoy conocemos un poco mejor el drama humano que acompaña a esta conducta.

Las sociedades modernas han sido negligentes en asumir este drama individual y colectivo, en sus causas y condicionantes, prefiriendo muchas veces negarlo, ocultarlo o disimularlo. Asumir el inmenso dolor que se esconde detrás del aborto supone un cuestionamiento profundo de nuestros comportamientos, creencias, valoraciones, motivaciones y compromisos. No es tarea fácil indagar en los orígenes del aborto y reconsiderar nuestras percepciones, sentimientos y comportamientos.

Quisiéramos conocer y acoger el sufrimiento asociado al drama del aborto provocado, pero no por esto podemos ocultar otros aspectos y sufrimientos. Es por ello que nos hacemos un deber de conciencia, profesional y humano, examinar con apertura y sentido crítico algunos planteamientos atingentes, para contribuir a orientar los esfuerzos de la sociedad hacia soluciones correctas.

Las sociedades contemporáneas se encuentran divididas acerca de cuáles son los caminos legítimos para enfrentar esta situación. Los partidarios de una liberalización de las leyes que penalizan el aborto, en casos de malformaciones graves o de embarazos productos de violación, sostienen que la sociedad no puede imponer a las mujeres el llevar a término esos embarazos contra su voluntad. En este contexto, se entiende que el Estado debe proveer los medios para la realización del aborto cuando éste sea requerido. La razonabilidad de la solicitud en cuestión se fundamenta sobre una exigencia que derivaría de los derechos adscritos específicamente a la mujer.

Los que se oponen a una liberalización de las leyes que penalizan el aborto, fundamentadas sobre la inaceptabilidad moral del mismo -exceptuando el espontáneo-, sostienen que una tal despenalización no va en el mejor interés ni de las mujeres ni de quienes están por nacer, ya que atenta contra la vida de un ser humano inocente e indefenso, no provee a la mujer de verdaderas soluciones, abandonándola a las presiones ilegítimas de su entorno, y deja sin sanción a los responsables.

En nuestra comunidad se encuentra abierta una discusión política sobre este tema, y no nos corresponde a nosotros -como Grupo de Estudios de Ética Clínica-abanderarnos en ese debate. Sin embargo, hemos considerado oportuno ofrecer a nuestros colegas y a la opinión pública, algunos elementos de reflexión que puedan ayudar a que la discusión ciudadana pueda ser más racional e informada.

Luego de un examen atento acerca de aquellos aspectos que atañen más directamente a la profesión médica, constatamos que la expresión "interrupción del embarazo" alude a un tema amplio y complejo, en el cual se entrecruzan aspectos técnicos, éticos, políticos que no son necesariamente compartidos entre los médicos. No obstante, hemos identificado tres temas que se relacionan con nuestra profesión, y hemos procurado desarrollar del modo más objetivo posible las realidades de orden médico y ético-médico subyacentes. Un examen crítico debería, como exigencia mínima, hacer explícitos las presunciones teóricas o prácticas de las expresiones utilizadas.

\section{Interrupción voluntaria del embarazo}

La expresión "interrupción voluntaria del embarazo" (IVE) es relativamente nueva en el ámbito médico y político, puede tener diversos significados y en distintos niveles. Por lo pronto, entenderla bien supone examinar cada uno de los tres conceptos que la componen. 
Por interrupción se entiende en castellano la detención momentánea o definitiva de un proceso, antes de su término. En el caso en comento lo que se intenta es una interrupción definitiva del embarazo, lo que equivale a su supresión.

En el ámbito médico se entiende habitualmente por IVE a la intervención que realiza el equipo médico-obstétrico durante el embarazo, con el objetivo de facilitar un trabajo de parto dificultoso, de posibilitar la sobrevida del feto, o de proteger la salud o la vida de la madre. También es posible conceptualizar esta intervención médica como un término anticipado del embarazo o una anticipación del parto. Para mayor claridad proponemos llamar a esta acción "interrupción del embarazo por razones médicas”. El término voluntario resulta redundante, ya que todo acto médico implica, por definición, voluntariedad de las partes.

En otro contexto, la expresión "interrupción voluntaria del embarazo" ha sido usada para significar la finalización del embarazo, antes de la viabilidad fetal. En el estado actual "antes de la viabilidad fetal" significa concretamente: gestación de 22 semanas, peso fetal de $500 \mathrm{~g}$, longitud céfalo-nalgas de $25 \mathrm{~cm}$, debiendo tenerse en cuenta que hay también un papel fundamental de la madurez pulmonar y el soporte médico y tecnológico ${ }^{2,3}$.

En otras ocasiones "interrupción voluntaria del embarazo" se entiende como terminación del embarazo, sin relación a la viabilidad o no viabilidad, y con intención y resultado de muerte para el ser en gestación. En este caso "IVE" viene a ser sinónimo de aborto, tal como lo ha recogido la reflexión jurídica chilena ("toda maniobra destinada a interrumpir el embarazo impidiendo que él llegue a su término natural, cual es el nacimiento del producto de la concepción"4) o, en el lenguaje corriente, "aborto provocado".

En el proyecto de ley, la primera causal invocada, esto es, el riesgo materno, la "interrupción voluntaria del embarazo" podría corresponder a la primera figura descrita, es decir, a una "interrupción del embarazo por razones médicas". No obstante, el proyecto no especifica que el riesgo vital sea por razones médicas y genera una dificultad interpretativa al introducir la distinción entre riesgo "presente o futuro". Esta última distinción no existe en la literatura ${ }^{5}$, es conceptualmente confusa y resulta, por lo mismo, inoperativa. El "daño eventual" que supone la noción de riesgo, y que ya incorpora la idea de futuro (en lo eventual), debe poder estimarse en el presente. Alguien puede aumentar o disminuir su riesgo actual, o ponerse en "situación de riesgo", por lo que se puede hablar propiamente de riesgo actual o potencial, pero no de riesgo futuro.

La segunda causal del proyecto, "por razones de alteración estructural congénita o genética incompatible con la vida extrauterina", y la tercera causal, que se refiere al embarazo producto de una violación, corresponderían actualmente a formas particulares del delito de aborto. Debe hacerse notar que en nuestro orden legislativo no existe la figura genérica de "interrupción voluntaria del embarazo" como delito tipificado, que sea susceptible de ser despenalizada en circunstancias específicas. Lo que existe es el delito de aborto, que corresponde a lo que el lenguaje común denomina "aborto provocado", para distinguirlo del "aborto espontáneo". El término "provocado" es superfluo para el derecho penal, ya que éste sólo se refiere a actos voluntarios; como asimismo el de "voluntario" es superfluo para la medicina, porque sobre el arte médico influyen e interactúan las voluntades de médico y paciente. Se trata, entonces, de despenalizar dos formas de aborto. Lo anterior queda explicitado en este proyecto cuando en él se agrega un tercer inciso, nuevo, al artículo $344 \mathrm{del}$ Código Penal: "No constituye delito de aborto la interrupción voluntaria del embarazo en los casos autorizados en el artículo 119 del Código Sanitario", con lo que queda claro que se trata de una despenalización del aborto, en las circunstancias especificadas, y no de una despenalización de la “interrupción voluntaria del embarazo".

Las precisiones conceptuales permiten sacar a la luz la heterogeneidad de las tres situaciones que el proyecto aspira a regular. En efecto, la primera de ellas se refiere a una realidad habitual de orden médico, las otras dos tienen que ver con situaciones que actualmente se encuentran reguladas en el Código Penal. Otro signo de la heterogeneidad de las situaciones es que el proyecto propone modificaciones tanto al Código Sanitario como al Código Penal.

\section{El “embarazo" y el "producto de la concepción”}

Las discusiones acerca de la IVE exigen precisar algunas expresiones que aparecen con frecuencia y que aluden a realidades distintas o a distintos 
aspectos de la realidad. Nos referimos en concreto a expresiones como "embarazo", "producto de la concepción”, "embrión”, "feto" o "niño por nacer".

La expresión "embarazo" alude directamente a un estado fisiológico y psicológico de la madre, que forma parte del proceso generativo humano. Es concebible que algún día, y en algunas circunstancias, el desarrollo humano pueda ser llevado a cabo de manera extrauterina, en virtud del progreso de la ciencia y de la técnica. Esta hipótesis, hoy en día irrealizable, permite distinguir mejor dos aspectos del proceso generativo humano que están íntimamente relacionados pero que son distintos. Uno es el estado de la madre, el otro es la generación y el desarrollo del hijo.

La interrupción del embarazo, entonces, tiene consecuencias directas en el correlato biológico del embarazo que es el individuo en desarrollo, por lo que -considerado en su integralidad- el aborto no es asunto privativo de la madre. El individuo en desarrollo es una entidad biológicamente independiente, aunque vinculada estrechamente a la madre. Por otra parte, no sólo es hijo de ella sino también de su padre. El proceso generativo humano posee por su naturaleza misma una dimensión social que otras funciones biológicas no tienen.

En el individuo humano en desarrollo es posible discernir etapas o períodos. Los términos: embrión, feto, niño, adolescente, adulto, anciano u otras, señalan estados o condiciones de un mismo individuo a lo largo de su desarrollo.

La palabra concepción corresponde, en castellano, al acto y efecto de concebir, a la vez que concebir es quedar preñada la hembra o formar idea o concepto de algo ${ }^{6}$. La expresión "producto de la concepción", tiene también significaciones diversas. En sentido amplio incluye todo tipo de realidades biológicas desencadenadas por la fecundación, abarcando a entidades que van desde la mola hidatiforme hasta el embarazo normal. En sentido más restringido y usual, "producto de la concepción” define al ser vivo en desarrollo en el seno materno. Desde el punto de vista biológico se suele entender que la vida de un individuo humano comienza en la fecundación, luego que el espermatozoide del varón y el ovocito de la mujer se unen para dar origen a un nuevo organismo denominado "cigoto". La nueva y original composición genética del cigoto aporta un criterio morfológico de individualidad y especificidad, que lo asimila a la especie de sus progenitores, por medio de su patrón cromosómico general, y lo distingue en lo individual por el genoma particular, al interior del patrón general de la especie ${ }^{7}$.

Algunos autores, como Austin, Burgess y otros, niegan que la fecundación pueda ser considerada como el criterio biológico para afirmar el comienzo de la vida humana, aduciendo los problemas de fisión o fusión en el blastocisto ${ }^{8,9}$. Otros adscriben la condición de humanidad a eventos específicos, como la implantación en el día $5^{\circ}$ post-fecundación, la aparición de la estría neural en el día $14^{\circ}{ }^{10}$, o cuando se comienzan a formar las diversas regiones cerebrales. No hay consenso en torno al hito decisivo, entre diversos autores.

Los progresos de la biología moderna han planteado a la humanidad el desafío de determinar con precisión cuál es el estatuto ontológico y ético del cigoto humano. Si bien es cierto que para el sentido común "un ser vivo de la especie humana es un ser humano", no es tan claro para todos que sea necesario reconocerle en plenitud al cigoto, el estatuto personal, cultural y jurídico de un ser humano, con todas las consecuencias que derivan de ello.

Ciertamente se trata de un debate filosófico y jurídico que se encuentra abierto. Sin embargo, desde el punto de vista médico, en particular en la interacción con nuestros pacientes (y el embrión o feto lo sería debido a su naturaleza personal ${ }^{11}$ ), no es claro que el profesional pueda abandonar sin razones justificadas los criterios sobre los cuales ha reposado y sigue reposando la vida personal y social, y según los cuales "un ser vivo de la especie humana es un ser humano".

\section{El aborto como acción de salud}

El proyecto de ley plantea como complemento a la despenalización del aborto la proposición de considerar la IVE en tres causales "como una legítima prestación de salud": riesgo inminente de la vida de la madre, inviabilidad fetal y embarazo por violación.

Dada la trascendencia de tal política y las consideraciones prácticas que supone esta proposición para el ejercicio de nuestra profesión, pensamos que debe ser examinada con detención.

En principio, lo que sea o no una acción médica parece venir determinado por la naturaleza 
misma de las cosas, y en virtud del reconocimiento que las personas profesionalmente competentes estén en condiciones de realizar. Cabe entonces preguntarse si corresponde al Estado substituir al arte médico en una tal determinación.

Así, reconocemos a la terapéutica como aquella parte de la medicina que enseña los preceptos y remedios para el tratamiento de las enfermedades ${ }^{6}$, como también, consideramos al acto médico como aquel acto electivo, realizado por un profesional cuyo campo de responsabilidad es primaria e irrenunciablemente la salud del paciente a su cargo, buscando como fin la prevención de la enfermedad o la recuperación de la salud, considerada ésta como un bien particular del hombre ${ }^{12}$.

Existen acciones que realiza el médico que no parecen ser estrictamente médicas, pero para las cuales el profesional está facultado u obligado por ley a realizar. Por ejemplo, la emisión de un certificado de nacimiento o de defunción, o la emisión de una licencia médica. Se trata aquí de actos que realiza el médico, ya sea como perito o ministro de fe, pero que no son actos médicos sino gestos con significación social. De hecho no están especificados como "prestaciones de salud".

En los últimos años se han suscitado en nuestro país conflictos entre médicos y administradores de salud cuando se pretende normar, por ejemplo, el tiempo de consulta, la prescripción de medicamentos, o la petición de exámenes con criterios extra-médicos, sean estos económicos o políticos. En caso que el médico siguiese estos criterios, pudiendo no hacerlo, y se produjese un daño al enfermo, ¿quién sería el responsable ante el derecho penal? ¿el médico, el político o el administrador? El derecho penal tiene respuesta clara a esta pregunta. Salvo imposibilidad física, el médico debe actuar como médico y con criterios médicos, y en base a ello será tenido por responsable ante la moral y la ley.

El distinto significado que propone el proyecto en comento, de transformar la "interrupción voluntaria del embarazo en tres causales" en una "legítima prestación de salud" implicaría la introducción por vía legal de una nueva acción médica.

Como ya se expresó, sólo la primera de las causales: riesgo inminente de la vida de la madre, alude a una situación propiamente médica, mientras que las dos siguientes son situaciones que el derecho penal chileno actual tipifica como aborto y que no son, primaria y estrictamente, problemas médicos. Sólo eventualmente pueden convertirse en un problema médico como, por ejemplo, un embarazo de alto riesgo en una niña violada o una crisis de angustia en razón del ultraje.

En caso de que este proyecto se aprobara, $y$ específicamente en la inviabilidad fetal y embarazo por violación, el médico estaría legitimado a realizar un aborto en virtud de una indicación "no-médica", lo que puede ser conceptualizado como una "indicación por razón estatal". Sería necesario, entonces, determinar si en estos dos casos el médico actúa como médico o como un agente del Estado. Esta situación no sería homologable a lo que ocurre cuando un médico emite un certificado de defunción o una licencia médica, ya que en esos casos expresa un juicio en calidad de perito del arte médico y no ejecuta una acción especial sobre el paciente.

\section{Conclusión}

Los médicos, en función de nuestra vocación y cercanía con los sufrimientos de nuestros pacientes, somos particularmente sensibles al entramado de circunstancias que pueden impulsar a participar en la realización de un aborto. Duele sobremanera constatar que la mayor parte de las veces la mujer es tanto o más víctima que el ser humano que está por nacer, y que inexorablemente muere en tal acto. No es nuestro rol -en cuanto médicoscondenar a la mujer que solicita la realización de un aborto o que se lo ha practicado. Sin embargo, estimamos como mejor solución propender al acogimiento, a la vez que se entregue el necesario sostén, tanto en lo humano como en lo técnico, a la mujer que crea estar en grave dificultad personal en relación con su embarazo, por lo que solicita ayuda médica.

Considerando todo lo anterior, en las deliberaciones llevadas a cabo en nuestro grupo, también nos hemos llegado a preguntar si acaso estamos dispuestos a actuar procurando la muerte de un ser humano, mandados por el Estado, al participar en una prestación otorgada por éste, y si ello sería compatible con la esencia de nuestra profesión, expresada en el Juramento Hipocrático ${ }^{13}$. La muerte de un ser débil e inocente parece ser más bien parte del problema, que no de las soluciones, las que debieran considerar el debido y efectivo apoyo que requiere quien se encuentra en situación de minusvalía o indefensión. 
Esperamos que estas consideraciones ayuden a nuestros colegas, para que cada uno reflexione sobre estas interrogantes y tome en conciencia las decisiones que mejor beneficien a sus pacientes, de acuerdo al estado actual de los conocimientos y el arte médico.

\section{Referencias}

1. República de Chile. Ministerio Secretaría General de la Presidencia. Mensaje de S.E. la Presidenta de la República con el que inicia un proyecto de ley que regula la despenalización de la interrupción voluntaria del embarazo en tres causales. 31 de enero de 2015. Disponible en: http://www.minsegpres.gob.cl/wp-content/upLoads/2015/01/1230-362-despenalia-interrupcion-emabrazo-3-causales-con-ingreso-camara.pdf (Consultado el 12 de agosto de 2015).

2. Neira J. Aborto, aspectos clínicos y epidemiológicos. Ars Medica 2002; 4(6):77-82.

3. Astete C, Beca JP, Lecaros A. Propuesta de un glosario para la discusión del aborto. Rev Med Chile 2014; 142: 1449-51.

4. Vivanco A. El aborto terapéutico: un nuevo intento de despenalizar el aborto en el Derecho chileno. Ars Medica, Vol. 18, n 18. Disponible en: http://escuela.med.puc. cl/publ/arsmedica/ArsMedica18/AbortoTerapeutico. html [consultado el 9 de abril de 2015].

5. Nunes IL. European Agency for Safety and Health at
Work. Occupational safety and health risk assessment methodologies. Disponible en: http://oshwiki.eu/wiki/ Occupational_safety_and_health_risk_assessment_methodologies (Consultado el 15 de agosto de 2015).

6. RAE. Diccionario de la Lengua Española. XXI edición. Madrid, 1992.

7. Santos MJ, Ventura-Juncá P. El inicio de la vida humana desde la perspectiva científica biológica. Ars Medica Vol 18. Disponible en: http://escuela.med.puc.cl/publ/ arsmedica/ArsMedica18/Inicio.html\# (Consultado el 9 de abril de 2015).

8. Austin CR. The significance of fertilization. Arch Biol Med Exp 1990; 23: 13-5.

9. Burgess J. Could a zygote be a human being? Bioethics 2010; 24 (2): 61-70.

10. Warnock M. Report of the Committee of Inquiry into Human Fertilization and Embriology. July 1984. London. Her Majesty's Stationery Office. Disponible en: http://www.hfea.gov.uk/docs/Warnock_Report_of_ the_Committee_of_Inquiry_into_Human_Fertilisation_and_Embryology_1984.pdf (Consultado el 12 de julio de 2015).

11. Besio M. El feto como paciente. MESVIDA, ULIA. Disponible en: https://es.scribd.com/doc/231020727/ MESVIDA-I-1-El-Feto-Como-Paciente-Mauricio-Besio. (Consultado el 6 de agosto de 2015).

12. Besio M. Sobre el acto médico. Cuadernos Bioética, 2003; 14 (50): 25-38.

13. Hipócrates. Juramento. En: Tratados, Gredos, Madrid, 1982. p. 38. 